\title{
Economic Evaluation of Beneficiating Nigerian Bentonite Using Periwinkle Shell and Mucuna Solannie
}

\author{
Kevin Chinwuba Igwilo, Anthony Kerunwa ${ }^{1, ~ *, ~ B a l a ~ S . ~ Z a k k a ², ~ I z u n n a ~ C h i n e m e l u m ~ O k e k e ~}{ }^{1}$ \\ ${ }^{1}$ Department of Petroleum Engineering, Federal University of Technology, Owerri, Nigeria \\ ${ }^{2}$ Department of Petroleum Engineering, University of Ibadan, Ibadan, Nigeria
}

Email address:

anthonykerunwa@rocketmail.com (A. Kerunwa)

${ }^{*}$ Corresponding author

\section{To cite this article:}

Kevin Chinwuba Igwilo, Anthony Kerunwa, Bala S. Zakka, Izunna Chinemelum Okeke. Economic Evaluation of Beneficiating Nigerian Bentonite Using Periwinkle Shell and Mucuna Solannie. International Journal of Oil, Gas and Coal Engineering.

Vol. 8, No. 5, 2020, pp. 116-123. doi: 10.11648/j.ogce.20200805.13

Received: September 12, 2020; Accepted: September 24, 2020; Published: October 17, 2020

\begin{abstract}
According to past studies, Nigerian Bentonites are found to be deficient in both fluid loss and rheological properties. Due to the deficiency of the Nigerian bentonite (NB), a good majority of bentonites used within Nigeria are imported. This research work seeks to evaluate the economic profitability of beneficiating the fluid loss and rheological properties of NB using periwinkle shell (PWS) and Mucuna Solannie (MS) as additives. The economic evaluation of this research seeks to point out the best possible action, based on available evidence. Two parameters - cost and outcome, are measured by the economic evaluation. From this measurement, an economic evaluation's results will not exactly point out the better alternative, the way that an experimental trial would. If the most effective option from the evaluation is the cheapest, then it is the most cost effective option. In such a scenario, the most cost effective option is said to be the dominant alternative. From the economic evaluation of the PWS and MS additives performed during the course of this research, it can be said that these additives are economically profitable when added to local bentonite (LB), compared to the cost of using imported bentonite (IB) clay. Estimation of required equipment and facility for processing of additives (PWS and MS), calculation of discounted cash flow rate of return (DCF - ROR) for the investment and sensitivity analysis on the cash flow assumptions were carried out for the achievement of optimum results.
\end{abstract}

Keywords: Bentonite, Mucuna Solannie, Periwinkle Shell, Economic Evaluation, Sensitivity Analysis

\section{Introduction}

Activities involving gas and oil exploration as well as (AWA) production exist virtually every part of the globe where hydrocarbon deposits are deemed to occur. In order to produce these hydrocarbons (HCs), the industry relies on a number of oilfield chemical formulations; one of such chemical formulations is the drilling fluid (DF). If the research findings on the market demand for DF are anything to go by, then it would be safe to infer that as DF demand increases, bentonite clay demand (one of the essential components of most DFs) would correspondingly increase. With this foreseen increase in demand, pressure would pile on the existing bentonite clay reserve sources; hence depleting it at a rate faster than hitherto anticipated. It must be noted that bentonite when added to fresh water to make a DF, plays a number of invaluable roles namely: to improve the hole cleaning properties of the fluid, reduce fluid loss to thief zones, create a thin and low permeability filter cake, cause stabilization of the borehole in formations that are poorly cemented $[1,2]$. Current bentonite clay consumption in drilling operations across Nigeria is put at estimation of above 50 thousand tons/year. However, the Nigerian oil industry spends a lot of money importing these foreign bentonite (FB) because her LB reserve doesn't meet the specifications required by API and hence, is a less preferred option to the expensive FB [3].

\subsection{Nigerian Bentonite and Its Characterization}

Nigeria has been blessed with an abundance of bentonite 
reserves and this would greatly reduce the importation of specialized DFs and ingredients, if properly harnessed. It has been reported that all regions in Nigeria possess a significant bentonite clay deposit and the country's bentonite reserves are put at the region of 700MM metric tons and above [4] with Edo State (Mid-Western Nigeria) being the largest shareholder and boasting a reserve of about 70-80MM metric tons of bentonite clay $[5,6]$. In 2003, the Federal Government placed a restriction on FB importation so as to promote the use of the large local deposits [7]. Irrespective of this restriction, the gas and oil industry has failed to utilize the LB clay deposits as there are no current reports of its use in drilling operations. Previous studies on DFs produced from strictly NB have demonstrated that such DFs have high fluid loss and poor rheological properties. This is likely due to poor quality of NB and hence the need for beneficiation [8]. As bentonite clay demand rises and with the movement of the activities of gas and oil exploration to deep offshore locations, it has become imperative for NB clays' properties to be enhanced so as to meet up with the API standard. The NB clays can be graded as Oil Company Material Association (OCMA) grade bentonite; thus requires a lot of beneficiation to make them meet the API bentonite standard $[9,10]$. The use of local materials [11] and sodium salt for the beneficiation of these clays has been largely employed [12] by various researchers in the conversion of montmorillonite clays that are calcium based into montmorillonite clays that are sodium based, with rheological properties that can be compared to API standard bentonite clays $[9,10]$. The mechanism occurs through the route of ion exchange that involves substituting calcium ions with those of sodium ions. Despite diverse studies on beneficiation of LB in the literature, there has not been any evaluation on the profitability of using PWS and MS for LB beneficiation. In this work, investigation on the economic evaluation of beneficiating NB using PWS and MS as local materials was conducted. This was necessary to ascertain the profitability of the project.

\subsection{Periwinkle Shell and Mucuna Solannie (PWS and MS)}

Periwinkle (Littorinalittorea) is a robust intertidal species of small edible sea snail with shells that are darkened and sometimes banded. Periwinkles originated in the northeastern rocky shores and later had their introduction to the northwestern part of the Atlantic Ocean. They can also be found in the Niger Delta region, Calabar and Badagry, located in the Southern and Western part of Nigeria respectively. PWSs are mostly regarded as waste and disposal has proved difficult over time, therefore leading to an accumulation of large shell deposits at various locations. Bringing this waste into the oil industry will be great as its shell contains elements that are viable for improving our local bentonite.

Mucuna as a genus consists of about a hundred species of the fabaceae family, a family of shrubs AWA climbing vines found in tropical woodlands of Asian and African countries [13]. The leaves has3-palmate, alternate or spiraledshape, with pea-like flowers AWA petals and distinctive curve. Mucuna seeds are toasted before grinding and flowering, and are mostly used as thickeners in soups, sauce, beverages as well as other local delicacies, by the Igbo in Southern Nigeria $[14,15]$. Also, research by Uwazuoke et al., (2016) has discovered that MS has the ability and elemental constituents to improve the quality of DFs [16].

\subsection{Principles of Economic Evaluation}

\subsubsection{Cost Benefit Analysis (CBA)}

Cost and decision making ties are essential to the analysis of strategy and important in understanding cost position and competitiveness in the long run [17]. CBA is an approach that systematically studies alternatives, estimates their strengths AWA weaknesses and determines or selects options which will provide a combination of achieving benefits and preserving savings. Opportunity cost is the guiding principle, and it refers to the sacrifice of alternatives foregone in the production of goods and services. There are two major applications of CBA [18]; to determine the soundness of an investment or decision AWA provision the basis for investments' comparison (comparing each option's total expected cost with its expected total benefits).

\subsubsection{Net Present Value (NPV)}

NPV is used for the evaluation of a number of alternatives. For cases involving a single alternative, the alternative is said to be viable if the Minimum Acceptable Rate of Return (MARR) is met or exceeded and this occurs when an investment's NPV at the MARR is greater than or equal to zero [16]. For cases involving two or more alternatives, the NPV at the MARR is calculated and compared, and the alternative which has the highest numerical NPV is selected. If all NPV's are negative, the negative NPV that is least is chosen. However, if all NPV's are positive, the most positive is chosen. In cases where there are both positive and negative NPV's, the more positive alternative is chosen.

Present Value, $P V=\frac{F V}{(1+i)^{n}}$, where $F V=$ Future Value, $\mathrm{i}=$ interest rate and $\mathrm{n}=$ number of periods. Note that the NPV is the total sum of all the PVs.

\subsubsection{DCF-ROR}

This is the interest rate made by the bank on an investment in a project. This evaluation technique is used on one alternative or to select between two or more alternatives [19], as soon as a MARR is stated. Accordingly, discounting at any rate in CBA simplifies the enormous future effects [20]. 'Discount rate' is usually used for PV and FV comparison. The DCF-ROR can also be described as the rate of interest that brings the NPV to zero. This means that if the DCF-ROR is calculated and its application made on the cash flow series, the NPV should be $\$ 0.00$. In the case of incremental analysis, DCF-ROR can also be used on two alternatives to check if the extra investment is profitable. If the calculated DCF-ROR from the increment in cash flow is greater than or equal to the MARR, the extra investment alternative is then selected [21], and if otherwise, it is rejected. For scenarios involving more 
than two alternatives, it can be used as an elimination tool to screen out all alternatives that have a DCF-ROR value which is less than the MARR.

\subsubsection{Sensitivity Analysis ( $S A)$}

$\mathrm{SA}$ is a technique that calculates the amount of impacts that uncertainty in one or higher input variables will have on those of output variable [22]. SA helps improve or reduce the model prediction by quantitatively and/or by understanding the studied phenomenon by variable interactions analysis or qualitatively studying the response of the model to input variables changes. However, we must not necessarily focus on the model output, but on the questions to be answered by the model. That is, the robustness of the model can be evaluated using the expected values of the parameters involved, and then, the values beyond which the output variable changes significantly, will be identified. SA helps improve knowledge by identifying priority needs.

\section{Materials and Methods}

\subsection{Purchasing and Processing of Locally-Sourced Materials and Additives}

The locally sourced materials are local (Nigerian) bentonite, PWSs and MS plant. IB was also used in the analysis. After local sourcing of the materials and additives, the additives (PWS and MS) were processed to enable usage. The PWS was washed to remove dirt particles, sun-dried to remove moisture and then grinded in a mill to powdered form. For MS, the seeds were removed, washed and dried to remove moisture, and then grinded to powder form.

\subsection{Determination of Elemental and Oxide Composition of Additives Using X-ray Diffraction Test}

To achieve an optimum level of accuracy and reliability, the elemental and oxide composition of the additives (PWS and MS) had to be known as it would indicate the major constituent element and also a good overview of the elemental and oxide distribution in the additives. This is important because, since we are trying to beneficiate LB, we need to know the elemental or oxide properties of the additives that will be responsible for the beneficiation process. Also, research has proven that NB is predominantly calcium-based and needs elements like sodium for beneficiation. This test was carried out in a spectral laboratory.

After the X-ray diffraction test was conducted on the additives, rheology and LTLP test (For fluid loss determination) were conducted on the three samples of bentonite (local, imported and beneficiated NB).

\subsection{Economic Evaluation of Beneficiation Process}

Since this is an alternative approach, it needs to be compared with the current system of using IB in terms of quality and cost-benefit.

The cost-benefit method used for economic evaluation of this beneficiation process involved the following steps:

1. The costs of purchasing and processing PWS and MS were recorded.

2. The costs of purchasing LB were recorded. Also, the costs of every needed equipment and facility were duly estimated.

3. The costs were projected over a period of five (5) years.

4. Discount rates were applied and the NPV was estimated.

5. The DCF-ROR was calculated.

6. SA was performed primarily to check the implications of variations in the factors affecting the proposed alternative (beneficiation process). These factors are revenue, investment and expenditure.

\section{Results and Discussions}

\subsection{Compositions of PWS and MS}

Tables 1 and 2 depict the composition of the elements of both PWS and MS obtained with the use of SEM. Table 3 depicts the composition of the oxides gotten with XRD technique. From the results, PWS had calcium $(\mathrm{Ca})$ of $77.67 \%$, which is in agreement with the work of [23], $\mathrm{CaO}$ of $57.61 \%, \mathrm{Al}_{2} \mathrm{O}_{3}$ of $9.99 \%$ and $\mathrm{SiO}_{2}$ of $14.05 \%$ in elemental AWA composition of the oxides while MS had potassium $(\mathrm{K})$ of $28.86 \%, \mathrm{SiO}_{2}$ of $4.82 \%$ and $\mathrm{Al}_{2} \mathrm{O}_{3}$ of $1.82 \%$. The $\mathrm{Ca}$ and $\mathrm{K}$ high content conveys to a great degree shale inhibition characteristics of PWS and MS during well drilling operations. Also, $\mathrm{SiO}_{2}$ and $\mathrm{Al}_{2} \mathrm{O}_{3}$ presence are among NPs which are known for effectively stabilizing the wellbore. The results revealed that PWS is primarily constituted of $\mathrm{Ca}(77.67 \%)$ with little quantity of $\mathrm{Na}$ of $0.23 \%$ which basically is what constitutes the FB while MS is primarily constituted of $\mathrm{C}(35.27 \%)$ and $\mathrm{K}$ $(28.86 \%)$. This indicates that the main elements of MS that aided the process of beneficiation were $\mathrm{C}$ and $\mathrm{K}$

Table 1. Elemental composition of PWS.

\begin{tabular}{|c|c|c|c|c|}
\hline Elements Number & Element Symbol & Element Name & Atomic Conc. & Weight Conc. \\
\hline 20 & $\mathrm{Ca}$ & Calcium & 77.67 & 79.48 \\
\hline 14 & $\mathrm{Si}$ & Silicon & 12.31 & 8.83 \\
\hline 47 & $\mathrm{Ag}$ & Silver & 0.77 & 2.13 \\
\hline 39 & $\mathrm{Y}$ & Yttrium & 0.94 & 2.13 \\
\hline 41 & $\mathrm{Nb}$ & Niobium & 0.65 & 1.55 \\
\hline 26 & $\mathrm{Fe}$ & Iron & 0.78 & 1.11 \\
\hline 19 & $\mathrm{~K}$ & Potassium & 1.04 & 1.04 \\
\hline 16 & S & Sulfur & 1.05 & 0.86 \\
\hline 13 & $\mathrm{Al}$ & Aluminium & 0.85 & 0.58 \\
\hline
\end{tabular}




\begin{tabular}{lllll}
\hline Elements Number & Element Symbol & Element Name & Atomic Conc. & Weight Conc. \\
\hline 8 & $\mathrm{O}$ & Oxygen & 1.02 & 0.42 \\
6 & $\mathrm{C}$ & Carbon & 1.08 & 0.33 \\
15 & $\mathrm{P}$ & Phosphorus & 0.27 & 0.21 \\
11 & $\mathrm{Na}$ & Sodium & 0.23 & 0.13 \\
12 & $\mathrm{Mg}$ & Magnesium & 0.20 & 0.13 \\
22 & $\mathrm{Ti}$ & Titanium & 0.10 & 0.13 \\
& $\mathrm{Thj}$ & & \\
\hline
\end{tabular}

Table 2. Elemental composition of MS.

\begin{tabular}{lllll}
\hline Element Number & Element Symbol & Element Name & Atomic Conc. & Weight Conc. \\
\hline 19 & $\mathrm{~K}$ & Potassium & 28.86 & 39.18 \\
6 & $\mathrm{C}$ & Carbon & 35.27 & 14.71 \\
15 & $\mathrm{P}$ & Phosphorus & 7.34 & 7.89 \\
30 & $\mathrm{Zn}$ & Zinc & 2.81 & 6.37 \\
26 & $\mathrm{Fe}$ & Iron & 2.63 & 5.11 \\
16 & $\mathrm{~S}$ & Sulfur & 4.54 & 5.05 \\
20 & $\mathrm{Ca}$ & Calcium & 3.27 & 4.55 \\
39 & $\mathrm{Y}$ & Yttrium & 1.15 & 3.54 \\
22 & $\mathrm{Ti}$ & Titanium & 1.84 & 3.06 \\
17 & $\mathrm{Cl}$ & Chlorine & 2.19 & 2.70 \\
8 & $\mathrm{O}$ & Oxygen & 3.74 & 1.95 \\
14 & $\mathrm{Si}$ & Silicon & 2.00 & 1.77 \\
13 & $\mathrm{Al}$ & Aluminium & 1.89 & 1.17 \\
12 & $\mathrm{Mg}$ & Magnesium & 1.39 & 0.86 \\
\hline
\end{tabular}

Table 3. Oxide composition of PWS and MS.

\begin{tabular}{lll}
\hline OXIDE & PWS & MS \\
\hline $\mathrm{CuO}$ & 0.002 & 0 \\
$\mathrm{NiO}$ & 0 & 0 \\
$\mathrm{Fe}_{2} \mathrm{O}_{3}$ & 0.982 & 0 \\
$\mathrm{MnO}$ & 0.037 & 0 \\
$\mathrm{Cr}_{2} \mathrm{O}_{3}$ & 0 & 0 \\
$\mathrm{TiO}_{2}$ & 0.167 & 0.029 \\
$\mathrm{CaO}$ & 57.608 & 0.583 \\
$\mathrm{Al}_{2} \mathrm{O}_{3}$ & 9.99 & 1.828 \\
$\mathrm{MgO}$ & 0 & 0.243 \\
$\mathrm{ZnO}$ & 0.01 & 0.003 \\
$\mathrm{SiO}_{2}$ & 14.047 & 4.816 \\
\hline
\end{tabular}

\subsection{Fluid Loss and Rheological Properties}

Table 4 depicts the fluid loss AWA rheological properties of FB, LB and BB. From the result, there was significant reduction of filtrate volume with the utilization of PWS and MS as additive for the control of fluid loss. 15g of FB at $600 \mathrm{rpm}$ gave dial reading of 27 while $15 \mathrm{~g}$ of LB at $600 \mathrm{rpm}$ gave dial reading of $18.5 \mathrm{~g}$ concentration and below at $600 \mathrm{rpm}$, the dial reading was 26 , which is lower than 27 and as such lower than that approved by API. Thus, PWS and MS as DF additives for improvement of the fluid's rheological properties are unviable prospects at concentrations that are not above 5g. Nigerian LB therefore do not have the satisfaction of API standard for dial reading of 600-rpm of above 30. Hence the need for rheological properties improvement is therefore necessary through beneficiation by increasing the additives' concentration. If the concentration of beneficiating agents is increased from $7-8 \mathrm{~g}$, the dial reading will definitely meet the API standard [24, 25]. From table 4 also, with the increase in the additives, the obtained filtrate volume decreased from $27 \mathrm{ml}$ to $12 \mathrm{ml}$ which meets the API standard in accordance with [24] which states that the acceptance of DF as additive for fluid loss is only when the used additives gives below $15 \mathrm{~mL}$ volume of filtrate loss over 30 minutes time. Thus at higher concentration of $7-8 \mathrm{~g}$ of the additives, volume of filtrate loss will be much lower which is excellent and again in agreement with API standard.

Table 4. Results for fluid loss and rheological tests conducted.

\begin{tabular}{|c|c|c|c|c|c|c|c|c|c|}
\hline & $\begin{array}{l}\text { FB } \\
(15 g)\end{array}$ & $\begin{array}{l}\text { LB } \\
(15 g)\end{array}$ & $\begin{array}{l}\text { FB } \\
(30 g)\end{array}$ & $\begin{array}{l}\text { LB } \\
(30 g)\end{array}$ & $\begin{array}{l}\text { LB (15g) +MS (1g) } \\
+ \text { PWS (1g) }\end{array}$ & $\begin{array}{l}\text { LB (15g) +MS (2g) } \\
+ \text { PWS (2g) }\end{array}$ & $\begin{array}{l}\text { LB (15g) +MS (3g) } \\
+ \text { PWS (3g) }\end{array}$ & $\begin{array}{l}\text { LB (15g) +MS (4g) } \\
+ \text { PWS (4g) }\end{array}$ & $\begin{array}{l}\text { LB (15g) +MS (5g) } \\
+ \text { PWS (5g) }\end{array}$ \\
\hline Fluid loss (ml) & 13 & 27 & 5 & 11 & 24 & 22 & 16 & 14 & 12 \\
\hline $600 \mathrm{rpm}$ & 27 & 18 & 52 & 34 & 18 & 19 & 22 & 23 & 26 \\
\hline 300rpm & 21 & 13 & 43 & 28 & 13 & 14 & 14 & 15 & 16 \\
\hline 200rpm & 15 & 8 & 32 & 21 & 9 & 9 & 9 & 9 & 10 \\
\hline 100rpm & 11 & 6 & 25 & 16 & 6 & 6 & 6 & 7 & 8 \\
\hline $6 \mathrm{rpm}$ & 8 & 4 & 17 & 10 & 4 & 4 & 4 & 4 & 5 \\
\hline
\end{tabular}

\subsection{Economic Evaluation of Beneficiation Process}

Table 5 depicts series of cashflows for the process of beneficiation. From table 5, the cash flow for the local BB was obtained by subtracting the expenses which includes the costs of PWS, MS, LB, and machine maintenance and vehicle petrol 
from the revenue. From Table 6, The initial cash flow with NPV of 110.4 was discounted at the rates of $10 \%, 15 \%$ and $30 \%$ which gave NPVs of \$47.16934, \$24.22991 and $-\$ 23.72884$ respectively. The various discount rates were plotted against the obtained cash flows in figure 1 and the DCF-ROR was obtained at the rate of $22 \%$ which brings the NPV to zero (ORR). It can be seen that the DCF-ROR of $22 \%$ is very good compared to the normal standard $10-15 \%$ required by oil companies. This implies that this alternative is reasonably efficient in returning the profits on investment.

Table 5. Cash Flow of Base Case for Beneficiation Process Alternative.

\begin{tabular}{|c|c|c|c|c|c|c|c|c|c|}
\hline \multirow{2}{*}{$\begin{array}{l}\text { Years } \\
\text { From Start }\end{array}$} & \multirow{2}{*}{$\begin{array}{l}\text { Revenue } \\
(\$ 1,000)\end{array}$} & \multirow{2}{*}{$\begin{array}{l}\text { Investment } \\
(\$ 1,000)\end{array}$} & \multicolumn{4}{|c|}{ Expenditure Breakdown (\$1000) } & \multicolumn{2}{|c|}{ Expenses } & \multirow{2}{*}{$\begin{array}{l}\text { Cash Flow } \\
(\$ 1,000)\end{array}$} \\
\hline & & & $\begin{array}{l}\text { Periwinkle } \\
\text { shells }\end{array}$ & $\begin{array}{l}\text { Mucuna } \\
\text { Solannie }\end{array}$ & $\begin{array}{l}\text { Local } \\
\text { Bentonite }\end{array}$ & $\begin{array}{l}\text { Machine } \\
\text { Maintenance }\end{array}$ & & & \\
\hline 0 & 0 & 150.6 & & & & & & 0 & -150.6 \\
\hline 1 & 150 & 0 & 18 & 16 & 35 & 20 & 10 & 99 & 51 \\
\hline 2 & 150 & 0 & 18 & 16 & 35 & 20 & 10 & 99 & 51 \\
\hline 3 & 150 & 0 & 18 & 16 & 35 & 15 & 10 & 94 & 56 \\
\hline 5 & 150 & 0 & 18 & 16 & 35 & 20 & 10 & 99 & 51 \\
\hline
\end{tabular}

Table 6. Incremental Analysis of beneficiation process alternative.

\begin{tabular}{|c|c|c|c|c|c|c|c|}
\hline Years From Start & Cash Flow & DR@10\% & PV@10\% & DR@15\% & PV@15\% & DR@30\% & PV@30\% \\
\hline 0 & -150.6 & 1 & -150.6 & 1 & -150.6 & 1 & -150.6 \\
\hline 1 & 51 & 0.90909 & 46.36359 & 0.86957 & 44.34807 & 0.76923 & 39.23073 \\
\hline 2 & 51 & 0.82645 & 42.14895 & 0.75614 & 38.56314 & 0.59172 & 30.17772 \\
\hline 3 & 56 & 0.75131 & 42.07336 & 0.65752 & 36.82112 & 0.45517 & 25.48952 \\
\hline 4 & 52 & 0.68301 & 35.51652 & 0.57195 & 29.7414 & 0.35013 & 18.20676 \\
\hline 5 & 51 & 0.62092 & 31.66692 & 0.49718 & 25.35618 & 0.26993 & 13.76643 \\
\hline
\end{tabular}

Where: $\mathrm{DR}=$ Discount Rate.

$\mathrm{PV}=$ Present Value.

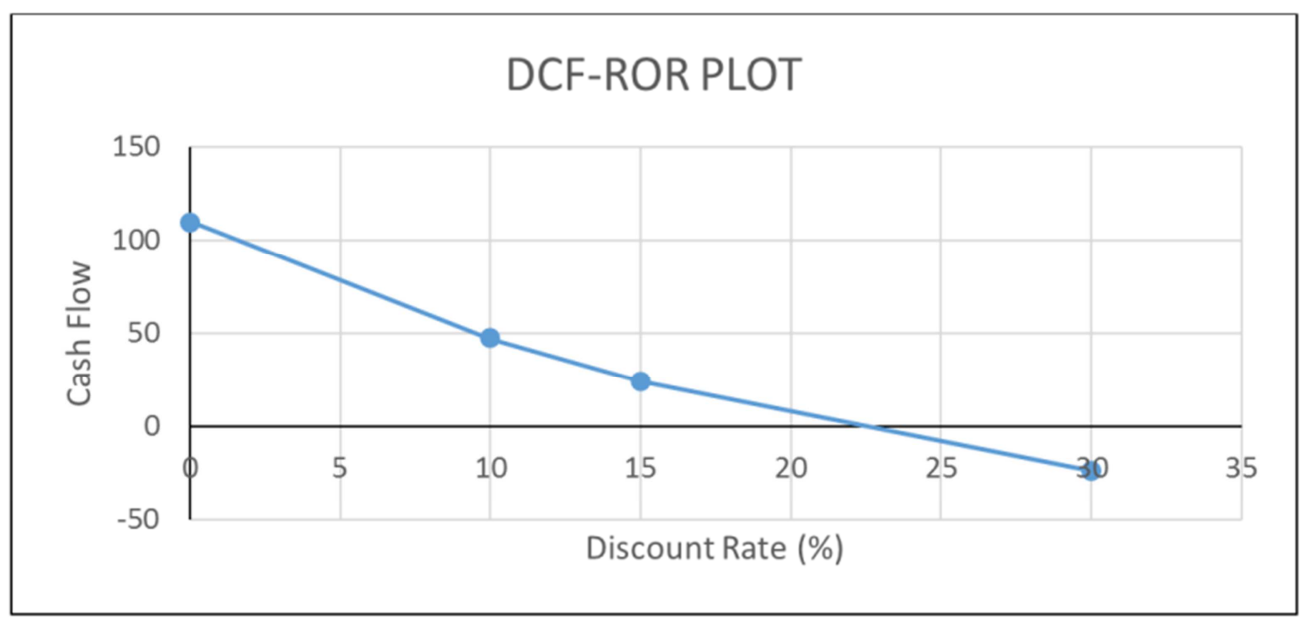

Figure 1. DCF-ROR plot.

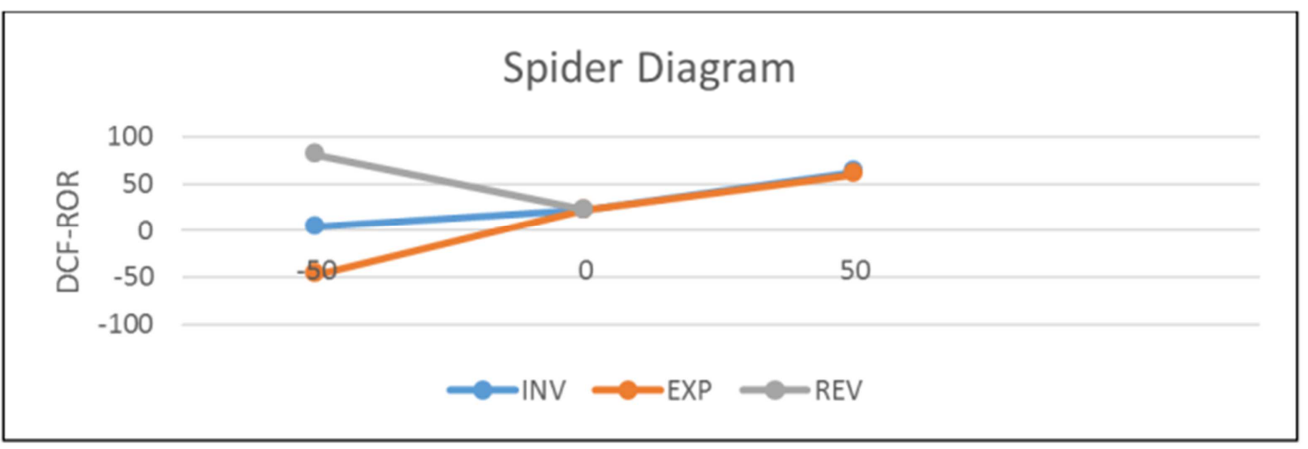

Figure 2. Spider Diagram on SA. 
Table 7. Sensitivity Analysis on Variations in Cash Flow Assumptions.

\begin{tabular}{|c|c|c|c|c|c|c|c|c|c|c|c|}
\hline $\begin{array}{l}\text { Years From } \\
\text { Start }\end{array}$ & Revenue & Expenses & Investment & Tax & Base Case & $\begin{array}{l}\text { INV + } \\
50 \%\end{array}$ & INV - 50\% & $\begin{array}{l}\text { EXP+ } \\
\mathbf{5 0 \%}\end{array}$ & $\begin{array}{l}\text { EXP - } \\
50 \%\end{array}$ & $\begin{array}{l}\text { REV+ } \\
50 \%\end{array}$ & $\begin{array}{l}\text { REV - } \\
50 \%\end{array}$ \\
\hline 0 & 0 & 0 & 150.6 & 0 & -150.6 & -225.9 & -75.3 & -150.6 & -150.6 & -150.6 & -150.6 \\
\hline 1 & 150 & 99 & 0 & 1 & 51 & 50 & 50 & 1.5 & 100.5 & 126 & -24 \\
\hline 2 & 150 & 99 & 0 & 1 & 51 & 50 & 50 & 1.5 & 100.5 & 126 & -24 \\
\hline 3 & 150 & 94 & 0 & 1 & 56 & 55 & 55 & 9 & 103 & 131 & -19 \\
\hline 4 & 150 & 98 & 0 & 1 & 52 & 51 & 51 & 3 & 101 & 127 & -23 \\
\hline 5 & 150 & 99 & 0 & 1 & 51 & 50 & 50 & 1.5 & 100.5 & 126 & -24 \\
\hline DCF - ROR & & & & & $22 \%$ & $4 \%$ & $61 \%$ & $-48 \%$ & $61 \%$ & $80 \%$ & N/A \\
\hline
\end{tabular}

It can be seen from the spider diagram, that for the base case shown in Figure 2 and Table 7, the DCF-ROR is 22\%. It is quite above the criteria of $10-20 \%$ rate acceptable in most companies. With a $50 \%$ increase in the value of investment, the DCF-ROR is $4 \%$. However, if there is a $50 \%$ reduction while maintaining same projected revenue, expenses and tax, as depicted in Table 7, the DCF-ROR is $61 \%$. Similarly, if there is a $50 \%$ increase in expenses, the DCF-ROR is negative with a value of $-48 \%$, but if there is a $50 \%$ reduction, the DCF-ROR is $61 \%$. Also, if there is a $50 \%$ increase in revenue, the DCF-ROR is $80 \%$, and if there is a $50 \%$ reduction in same, the table shows that there are extreme losses over the 5-year period. The NCR which is the cumulative cash-flow for a period of 5 years is $\$ 110,400$. The PO is about 2.9 years and the DCF-ROR is $22 \%$.

\subsection{FB and Local BB Cost Comparison}

Table 8 depicts the cost estimates of materials and ICF series respectively for the process of beneficiation. From table 8 , the sum total of the purchase of items for the local
$\mathrm{BB}$ is quite cheaper than that of FB. Therefore beneficiation of LB as an alternative to the FB is a reasonable and better option. Developing an ICFs between the two alternatives is the most preferred way to compare the foreign IB and the local $\mathrm{BB}$ by subtracting the cash flows of the FB (Case A) from the cash flows of the local BB (Case B) as shown in table 9. The ICF with a NPV of $\$ 453.4$ as depicted in table 10 was discounted at the rate of $10 \%$ which gave a NPV of $\$ 307.326224$ which did not give an ORR. The ICF was further discounted at the rates of $15 \%$ with a NPV of $\$ 254.365088$. Again, the incremental cash was discounted at the rate of $30 \%$ with a NPV of 143.690544 which did not give an ORR. Furthermore, the ICF was discounted at the rate of $60 \%$ and $100 \%$ with NPVs of 31.526536 and -33.575 respectively. The DCF-ROR plot depicted in Figure 3 intersected the discount rate at $75 \%$ which gave an ORR. The intersection at the rate of $75 \%$ shows that the local BB will reduce the cost spent on drilling mud by $75 \%$ compared to the foreign IB. This implies that this alternative (local BB) is reasonably efficient in returning the profits on investment.

Table 8. Cost estimates of materials.

\begin{tabular}{llll}
\hline S/N & Item description & Size (metric tons) & Unit Price (\$) \\
\hline 1 & Foreign bentonite & 1 & 305.4 \\
2 & Local bentonite & 1 & 150.6 \\
3 & Periwinkle shell & 1 & 18 \\
4 & Mucuna solannie & 1 & 16 \\
\hline
\end{tabular}

Table 9. Incremental Cash flow Series.

\begin{tabular}{llll}
\hline Years & Case A & Case B & Incremental (case B - case A) \\
\hline 0 & 0 & -150.6 & -150.6 \\
1 & -305.4 & -184.6 & 120.8 \\
2 & -305.4 & -184.6 & 120.8 \\
3 & -305.4 & -184.6 & 120.8 \\
4 & -305.4 & -184.6 & 120.8 \\
5 & -305.4 & -184.6 & 120.8 \\
TOTAL & -1527 & -1073.6 & 453.4 \\
\hline
\end{tabular}

Case $\mathrm{A}=\mathrm{FB}$.

Case $\mathrm{B}=$ Local $\mathrm{BB}$.

Table 10. Incremental Analysis of beneficiation process alternative.

\begin{tabular}{|c|c|c|c|c|c|}
\hline Years From Start & Cash Flow & DR@10\% & PV@10\% & DR@15\% & PV@15\% \\
\hline 0 & -150.6 & 1 & -150.6 & 1 & -150.6 \\
\hline 1 & 120.8 & 0.90909 & 109.818072 & 0.86957 & 105.044056 \\
\hline 2 & 120.8 & 0.82645 & 99.83516 & 0.75614 & 91.341712 \\
\hline 3 & 120.8 & 0.75131 & 90.758248 & 0.65752 & 79.428416 \\
\hline 4 & 120.8 & 0.68301 & 82.507608 & 0.57195 & 69.09156 \\
\hline 5 & 120.8 & 0.62092 & 75.007136 & 0.49718 & 60.059344 \\
\hline TOTAL & 453.4 & & 307.326224 & & 254.365088 \\
\hline DCF-ROR & $75 \%$ & & & & \\
\hline
\end{tabular}


Table 10. Continued.

\begin{tabular}{|c|c|c|c|c|c|c|}
\hline Years From Start & DR@30\% & PV@30\% & DR@60\% & PV@60\% & DR@100\% & PV@100\% \\
\hline 0 & 1 & -150.6 & 1 & -150.6 & 1 & -150.6 \\
\hline 1 & 0.76923 & 92.922984 & 0.625 & 75.5 & 0.5 & 60.4 \\
\hline 3 & 0.45517 & 54.984536 & 0.24414 & 29.492112 & 0.125 & 15.1 \\
\hline 4 & 0.35013 & 42.295704 & 0.15259 & 18.432872 & 0.0625 & 7.55 \\
\hline 5 & 0.26993 & 32.607544 & 0.09531 & 11.513448 & 0.03125 & 3.775 \\
\hline TOTAL & & 143.690544 & & 31.526536 & & -33.575 \\
\hline DCF-ROR & & & & & & \\
\hline
\end{tabular}

\section{Conclusion and Recommendation}

\subsection{Conclusion}

From the results gotten and analysis made, it can be inferred that:

(a) The beneficiation process is very economically beneficial and a good potential for the oil industry.

(b) The additives (PWS and MS) have proven to contain and provide enough properties to be able to enhance our local bentonite if added in substantial amounts.

(c) With the DCF-ROR of $22 \%$, the Nigerian oil industry has a lot to benefit from this approach.

(d) Also, considering that drilling and production operations are long term processes, this process will be beneficial at the long-run as investment is made only once and annual cash flows are positive indicating profits.

\subsection{Recommendation}

While conducting the tests, evaluating the cost benefit and also analyzing the results, it was noticed that the additives were not sodium based but still yielded profitable results. Therefore, we would recommend that more research should be conducted with a combination of snail shells as additives.

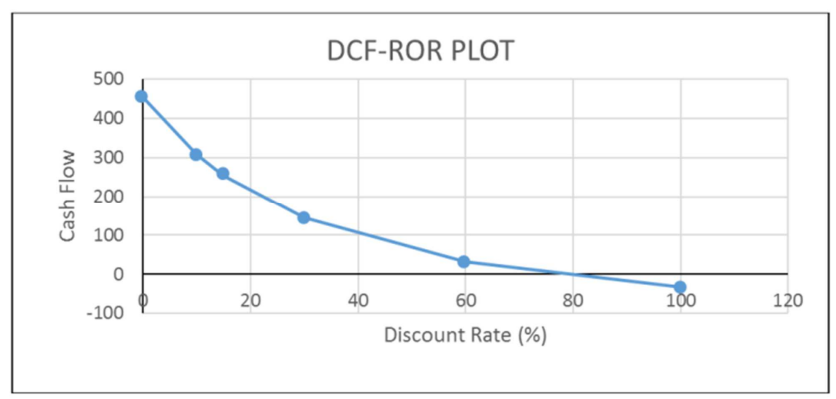

Figure 3. DCF-ROR plot.

\section{Nomenclature}

AWA - As well as

DF - Drilling fluid

$\mathrm{HC}$ - Hydrocarbon

HCs - Hydrocarbons

DFs - Drilling fluids

API - American Petroleum Institute
LB - Local Bentonite

FB - Foreign Bentonite

NB - Nigerian bentonite

$\mathrm{BB}$ - Beneficiated Bentonite,

OCMA - Oil Company Material Association

MARR - Minimum Acceptable Rate of Return

PV - Present value

PVs - Present values

PO - Payout

LTLP - Low temperature low pressure

YP - Yield Point

PV - Plastic Viscosity

IB - Imported Bentonite

MS - MucunaSolannie

PWS - Periwinkle Shell

PWSs - Periwinkle Shells

NPV - Net Present Value

DCF - ROR - Discounted Cash Flow Rate of Return

CBA - Cost-Benefit Analysis

ICF - Incremental cash flow

ICFs - Incremental cash flows

SEM - Scanning Electron Microscope

NPs -Nanoparticles

ORR - Optimum return rate

CMC - Carboxymethyl cellulose

\section{References}

[1] Chilingarian G. V. and Vorabutr P. (1983). Drilling and drilling fluids. Elsevier, Amsterdam, pp 149-151.

[2] Elward-Berry J. and Darby J. B. (1997). Rheologically stable, nontoxic, high temperature, water based drilling fluid. SPE Drill Complet. 12 (3): 158-162.

[3] Odumugbo C. A. (2005). Evaluation of local bentonitic clay as oil drilling fluids in Nigeria. SPE 85304.

[4] Omole O, Adeleye J. O., Falode O., Malomo S. and Oyedeji O. A. (2013). Investigation into the rheological and filtration properties of drilling mud formulated with clays from Northern Nigeria. J Petrol Gas Eng 4 (1): 1-13. https://doi.org/10.5897/JPGE0 9.017.

[5] Nweke, O. M., Igwe, E. O., Nnabo, P. N., (2015). Comparative evaluation of clays from Abakaliki formation with commercial bentonite clays for use as drilling mud. Afr. J. Environ. Sci. Technol. 9 (6): 508-518. http://dx.doi.org/10.5897/AJEST2015.1904. 
[6] Nweke, O. M., (2015). Evaluating the suitability of clays from Abakaliki Area, South-eastern Nigeria for oil industrial application using geotechnical and rheological properties. Sci. Innov. $\quad 3 \quad$ (2): $22-31$. http://dx.doi.org/10.11648/j.si.20150302.11.

[7] Oriji, A. B., Lawal, F. S., Bala, Z., (2014). Evaluating the efficiency of Nigerian local bentonite as an extender in oil well cementation. Chem. Process Engrg. Res. 28, 78-88.

[8] Abdullahi, A. S., Ibrahim, A. A., Muhammad, M. A., Kwaya, M. Y. and Mustapha, S. (2011). Comparative Evaluation of Rheological Properties of Commercial Bentonite and Locally Beneficiated BentoniticClay from a Marine Deposit in Upper Benue Basin, Nigeria. British J. of Applied Sci. and Techn., 1 (4): 211-221.

[9] Salam, K. K., Adeleye, O. J., Arinkoola, A. O., (2010). Evaluation of rheological properties of beneficiated locally sourced mud using factorial design. Int'l J. Oil, Gas Coal Technol. 3 (2), 144-159.

[10] Dewu, B. B. M., Funtua, I. I., Oladipo, M. O. A., Arabi, S. A., Mohammed-Dabo, I. A., Muhammad, A. M. and Hamidu, I. (2011). Evaluation and Beneficiation of Bentonitic Clays from Pindiga Formation in Benue Trough. American J. of Eng. and Applied Sci., 4 (4): 497-503.

[11] Udoh F. D. and Okon A. N. (2012). Formulation of WaterBased Drilling Fluid Using Local Materials. Asian J. Microbiol. Biotech. Envt. Sci., 14 (2): 167-174.

[12] Ibrahim A. O., Momoh O. R. and Isa M. T. (2017). Enhancement of Gambe Clay using Un-Fermentable Polymers for Drilling Mud Formulation. Nigerian J. Techno., 36 (1): 119.

[13] Obiakor-Okeke P. N., Chikwendu J. N., Anozie T. (2014). Effect of Different Processing Methods on the Chemical, Functional and Microbial Properties of Mucuna sloanei Seeds. Int. J. Nutrition and Food Sci. 3 (6): 551-559.

[14] Afolabi O. A, Oshuntogun B. A, Adewusi S. R, Fapojuwo O. O, Ayorinde F. O, Grisson F. E and Oke O. L (1985). Preliminary nutritional and chemical evalution of raw seeds from mucuna solannie. An underutilized food source. J. Agric. food chemistry, (38): 122-124.
[15] Ukachukwu S. N, Ezeagu I. E, Tarawall G. and Ikeorgu J. E. G. (2002). Utilization of Mucuna as a food and feed: Current uses and the way forward. R. J Workshops, CIDICCO, CIEPCA and World Hunger Research Center, Tegucigalpa, Honduras, pp. 189-287.

[16] Uwaezuoke N., Obah B., Onwukwe S I., Igwilo, K C. (2016). An Economic Evaluation of Investment in Mucuna solannie Production. Int'l J. of Envt, Agriculture and Biotechn. (IJEAB). 1 (3): 610-620.

[17] McGee J. (2019). Cost analysis. Vol. 1, p. 1-6.

[18] Hwang K. (2016). Cost-benefit analysis: its usage and critiques. J. Public Affairs. 16 (1): 75-80.

[19] Kerunwa A., Ariche P. O. and Izuwa N. C. (2020). Economic Evaluation of Hydraulic Fracturing in a Gas Condensate Reservoir Operating below Dewpoint. Open J. Yangtze Gas and Oil, 5 (3): 73-86.

[20] Ackerman F. and Heinzerling L. (2002). Pricing the Priceless: Cost-Benefit Analysis of Environmental Protection. Uni. of Pennsylvania Law Review 150, 1553.

[21] Blank L. and Tarquin A. (2002). Engineering Economy 5Ed. 1221 Avenue of the Americas, New York, NY 10020, McGraw-Hill, pp 172-173, 266-299, 621-653.

[22] Andronis L., Barton P. and Bryan S. (2009). Sensitivity analysis in economic evaluation: An audit of NICE current practice and a review of its use and value in decision-making. Health Techno. Assessment; 13 (29): 1-84.

[23] Salahudeen N. and Ahmed A. S. (2016). Effect of Beneficiation on the Characteristics of Gambe and Pindiga Bentonitic Clays. J. Mod. Chemist. Chemical Techno., 7 (2): 20-26.

[24] API, 13A (1993) Specifications for drilling fluids materials. 1220 L Street, NW Washington, DC 20005, USA.

[25] Afolabi R. O. Ogunkunle T. F. Olabode O. A. and Yusuf E.O. (2018). Dataset on the beneficiation of a Nigerian bentonite clay mineral for drilling mud formulation. Data in Brief (20): 234-24. 